\title{
Modeling Per Capita Demand of Wood Products in Greece: Variables with Impact to Demand and Forest Management Implications
}

\author{
Panagiotis P. Koulelis (Corresponding author) \\ Institute of Mediterranean Forest Ecosystems \& Forest Products Technology \\ Terma Alkmanos, 11528 Athens, Ilisia, Greece
}

Tel: 30-210-778-6175 ext.142Ｅ-mail: pkoulelis@ fria.gr

Evangelia N. Daskalakou

Institute of Mediterranean Forest Ecosystems \& Forest Products Technology

Terma Alkmanos, 11528 Athens, Ilisia, Greece

Tel: 30-210-778-6175 ext.142Ｅ-mail: edaskalakou@ fria.gr

Received: June 13, 2017 Accepted: July 28, 2017

doi:10.5296/emsd.v6i2.11735 URL: https://doi.org/10.5296/emsd.v6i2.11735

\begin{abstract}
The current study presents the trends of wood product trade in Greece during the last several decades. Greece, like many Mediterranean countries, is a net importer of wood and wood products and has established a consecutive dependency on imports during the past few decades. Variables like income and import prices are tested in order to highlight their meaningfulness on the demand for wood and wood products. Analysis based on multiple linear double log models showed that import prices were found to be the most important variable for wood panels and paper demand. Simultaneously, income was found to be the most important for wood fuel demand, as was expected. Income and import prices were found to be elastic regarding the demand for wood panels and paper. More, income was found to be inelastic to wood fuel demand. Further analysis of the above factors suggests a new forest policy plan based on the development of the current forest ecosystems and the creation of new forests through afforestation and reforestation, using native species in order to constrain the amount of expensive imports. From this perspective, a new forest policy based on sustainable forest management could lead to the increase of production and new
\end{abstract}


investments in the national forest sector.

Keywords: Wood products, Greek forest sector, demand modeling, sustainable forest management

\section{Introduction}

Mediterranean countries are, globally, net importers of wood and wood products. Despite the fact that Mediterranean forest products and services have represented a fundamental factor in the life of local inhabitants for centuries, few studies have focused on them on a large scale (UNEP/MAP-Plan Bleu, 2009; FAO 2013a), especially with regards to southern areas. Mediterranean forest ecosystems provide multiple wood and non-wood forest goods and services, which are crucial for the socioeconomic development of rural areas, as well as for the welfare of the urban populations of the Mediterranean region (Palahi et al., 2008). In 2010, according to the Food and Agriculture Organization Mediterranean countries collectively imported wood and wood products to the value of more than US\$40 billion, of which 80 percent, or US\$32 billion were from non-Mediterranean countries (FAO, 2013a).

A main characteristic of Greece is that most of the forest area is located in areas with high mountains and slopes, and therefore the production is limited. Koulelis (2009) placed Greece among EU countries with low productivity. Greek forests mainly produce: i) Logs for the production of sawnwood that is used mostly by the state power company or communications companies or as mining timber. ii) Wood chips to produce particleboard, MDF, paper and pellets. The exploitation of the above wood is not efficient. Most of this kind of wood stays unexploited in the forests that are exposed to climate conditions because the harvesting procedures are not cost-effective. Also, the residues of the logging (branches and peaks with diameter $<6 \mathrm{~cm}$ ) are also abandoned in the forest due to the high cost of harvesting and their natural usage as soil fertilizers. iii) Firewood mostly from oak, beech and chestnut which is more profitable than if it were used for pellets due to the good market prices of firewood.

Regardless of what the wood is used for, forests that are currently managed in a sustainable way are also characterized by pure management mostly due to a lack of resources and an insufficient national forest policy. The domestic demand is mostly covered by imports from commercial firms. A lot of attention is given to the protection and maintenance of forests and less to the improvement of the national forests or to afforestation. The domestic production, as it was expected, is insufficient to meet the needs of the consumers. However, Greek forests provide several goods and services such as hydrological, aesthetic, soil protection, enrichment of groundwater and other environmental functions that are very important for the country's economy and the quality of life of the population (Georgiadis and Cooper, 2007).

According to Koulelis (2011), Greek wood product imports have increased rapidly over recent years, which has both economic and ecological implications. There were some changes after 2008, during the economic crisis. The levels of consumption per capita of forest products in the cases of all products declined, mainly due to the collapse of the construction industry (Koulelis, 2016). Koulelis (2016) observed that the decrease of the deficit in forest products happened due to an increase in exports that had a positive impact on the deficit. In 
addition, according to FAOSTAT the imports of forest products that were measured in $\mathrm{m}^{3}$ declined by $54 \%\left(2.011 .810 \mathrm{~m}^{3}\right.$ in 2008 to $916.246 \mathrm{~m}^{3}$ in 2014) and the imports in tons saw a slight increase by $0.06 \%$ ( 847.380 tons in 2008 to 897.287 tons in 2014).

This study consists of two parts. The first part includes a quantitative analysis based on historical data collected over a long time period in relation to production, consumption and trade balance for three selected wood products categories that are important for Greece. This part presents the trends of wood products trade during the last 40 years. The second part of the analysis investigates the impact of variables like income and import prices to the demand for four selected wood products categories. For the following analysis, apparent consumption has been calculated to establish and compare the demand for wood products. It particular the analysis will show what the most important variable is from the above list that seems to play role in historical changes in demand. Understanding the meaningfulness of each variable could be useful as a tool by decision makers regarding future forest management plans. For this purpose, a multiple linear log-log model was employed that is suggested widely in the literature. There are not a lot of studies concerning wood products consumed or produced in Greece. One of them which is related to the consumption is from Arabatzis and Klonaris (2009) where the Greek wood imports and their relationship to the consumption and the national economy are analyzed. Globally, the modelling approach applies the methodology of Kangas and Baudin (2003); used in EFSOS I (UN, 2005) for providing projections of supply, demand and trade as regards processed wood products. Similar methodologies are reported in other studies with long term projections for the forest sector such as successor EFSOS II (UNECE, FAO 2012), the Global Forest Products Model GFPM (Buongiorno et al. 2003), FAO Global Forest Products Outlook Study (Zhu et al. 1998) and ETTS V (Baudin and Brooks 1995). Jonsson (2012) reported that according to EFSOS II (UNECE, FAO 2012) the consumption of Greece in wood and wood products until 2030 using both scenarios (A1 scenario: a future world of very rapid economic growth) and (B2 scenario: more emphasis is on local solutions to economic, social, and environmental sustainability) will increase in all the examined wood categories. Especially under the A1 scenario, the increase will be more intense. The same study also provides demand elasticities regarding GDP and imports prices for every major category. It's crucial to underline here that the above model logically couldn't take into account the upcoming national economic crisis and actually is based on growth of GDP (from $0.8 \%$ to $2.1 \%$ growth from 2006 to 2030 every four years). Projection that didn't occurred especially after 2009. In 2014, the levels of GDP were under the 22,000 \$ per capita, following an important decrease of $32.6 \%$ compared to 2008 (Koulelis, 2016).

The main purpose of this paper is to identify the main variables that have an important impact on the demand. This approach will take place by constructing demand functions. In addition, this multiple variable approach simulates real conditions modeling all the variables that impact together, but this does not imply that this analysis entirely covers the subject.

\section{Materials and Methods}

The main explanatory variables that will be used are: a) The income expressed by the Gross Domestic Product per capita on time t b) The import prices on time t. 
Economic growth, measured by the rate of change in Gross Domestic Product is generally associated with a growing demand for products and services, including wood products (Jonsson, 2011). The use of GDP (and sometimes population) is very common to the forest sector models that are defined by Solberg (1986). EFSOS (European Forest Sector Outlook Study) model (Kangas and Baudin, 2003), the Global Forest Products Model (Buongiorno et al., 2003) and EFSOS II (UNECE/ FAO, 2011) use GDP as the variable that best reflects economic growth to make projections about forest products' demand, supply and trade in Europe and globally.

There is no doubt that import prices have an impact on demand. For the calculation of the prices, the unit value of imports (import value/import volume) was used, as Buongiorno (1978) suggested for countries that are net importers. Actually, he suggested the usage of unit value of imports for net importers and the unit value of exports for net exporters.

The main source of quantity data is the UNECE/FAO Statistical Database (FAOSTAT, 2016). Quantity data consist of production and imports of commodities as well as the imports prices (Unit Price in US $\$$ per $\mathrm{m}^{3}$ or MT). More specifically the categories sawnwood + (total), wood panels + (total), paper and paperboard + (total) and fuel wood + (total) were used as defined by FAO (FAO, 2010). In order to determine that there is a statistically significant relationship between the variables, a multiple log-log linear regression analysis was applied. Multiple linear regression analysis was undertaken based on the following equation:

$$
\text { Cons }_{t}=f\left(P_{t}, G D P_{t}\right) \text { or } \ln \text { Cons }_{t}=a+b * \ln G D P_{t}+d * \ln P_{t}
$$

Where Cons $\mathrm{t}_{\mathrm{t}}$ is the consumption of the commodity on time $\mathrm{t}, \mathrm{P}_{\mathrm{t}}$ the import prices per unit in US \$ on time t, $\mathrm{GDP}_{(\mathrm{t})}$ the real Gross Domestic Product per capita on time $\mathrm{t}$ and $\mathrm{a}, \mathrm{b}$ and $\mathrm{d}$ the estimated coefficients. The functional form is double log-linear, allowing for direct interpretation of estimated coefficients as elasticities. In particular, b is income demand elasticity and $\mathrm{d}$ is import price elasticity. The explanation for the above is presented below:

In a double log function

$$
\log (Y)=a+b * \log (X) \text { the elasticity } \varepsilon \text { is } \quad \varepsilon=\frac{b Y}{X} * \frac{X}{Y}=b
$$

In addition, more variables on the right hand side don't change the assessment of $\varepsilon$.

The particular methodology, described in Buongiorno (1977, 1978) and in Baudin and Lundberg (1987), is further developed in Baudin and Brooks (1995) and it has been used many times in the past. Nevertheless, is reported that reducing the operational environment to the price and GDP may lead to oversimplification of the market analysis Hurmekoski (2015). Also, understanding what the underlying factors are that drive the possible changes in the GDP and prices elasticities themselves remains largely unclear. More specifically for the examination of the sawnwood consumption, the same author suggests that apart from the GDP and prices renovation activity, residential construction activity, unemployment, economic openness or even and abundant of forest resources could play a role; however, the models were unable to explicitly capture this connection. Regardless, the selection of the 
above approach serves as the baseline of the current analysis which is mostly based in econometrics.

Equation 1 is actually a multiple regression equation, so a multiple regression analysis will follow. Multiple regression analysis is a flexible method of data analysis that can be used when the dependent variable is studied in isolation or in relation to independent variables (Cohen and Cohen, 1983). Also it contributes heavily to the manufacture of predictable models (Draper and Smith, 1981). In addition, it can be used as a dynamic and precise data analysis tool. Regression provides all the essential mechanisms for statistical affairs, estimates and dynamic analyses (Cohen and Cohen, 1983). After the construction of the equation, the accuracy of the process was tested using the basic statistical tests of regression, including coefficient of determination $R^{2}$, Coefficients Standard Errors (CSE) and the significance $(p<0.05)$. As a base for regression it was assumed that the source population is normally distributed around the regression and the variance of the dependent variable in the source population is constant regardless of the value of the independent variable. One simple and important diagnostic of multicollinearity is the variance inflation factor (VIF) (Matis 2004). When the value of VIF is bigger than 10, there are redundant variables in the regression model and the parameter estimates may be unreliable. To identify the most important variables (meaningfulness) in regression models, the standardized coefficients were calculated. It's easy to think that variables with larger coefficients are more important because they represent a larger change in the depended variable. However, the units in most of the times vary between the different types of variables, which make it impracticable or unfeasible to compare them directly. Also $p$-value calculations incorporate a variety of properties, but a measure of importance is not among them. A very low $p$-value can reflect properties other than importance to the equation, such as a very precise estimate and a large sample size. It's well-known that variables that are crucial in the real world can have very low $p$-values. A statistically significant result may not be practically significant (Frost, 2016). Considering the above, the usage of standardized coefficients (largest absolute value) is having an advantage comparable to the coefficients of the model. The standardized regression coefficients represent the change in response for a change of one standard deviation in a predictor (Dallal, 2001). The statistical analysis was performed with XLSTAT Version 2016.03.30743 statistical package.

\section{Results and Discussion}

a) Industry characteristics

As was underlined above, the dependence of imports for Greece is obvious and Greece is heavily dependent on imports from other European countries (Sweden, Bulgaria, Romania, Finland, etc.), Russia and Asia (China, Indonesia etc.). During the last decade and more obviously due to the economic crisis (after 2010), the quantity of imports has decreased. At the same time, it is very well known that most enterprises are transforming into commercial companies or are closing. Some details regarding the capacity of the wood industry in Greece can surely help to understand the need for imports. The cost of importing is large, and it creates problems in the trade balance index and weakens the national economy. Although, the 


\section{Macrothink}

private forest sector enterprise in Greece utilizes significant quantities of domestic wood fiber. There are a small number of firms that produce particle board, melamine, veneered panels (using purchased veneers), kitchen benches and doors. Greece also has 65 pallet manufacturers $^{1,}$ but the vast majority of which are small scale. There are also 30 parquet flooring manufacturers, two of which are reasonably large companies (ETTF, 2011). Only a few big enterprises use automatic optimized sawing pattern technologies and have an annual production over than $30000 \mathrm{~m}^{3}$ per year. In addition, there are almost 100 sawmills that use old machinery, mainly small enterprises, and only ten of them have a capacity of $5.000-30.000 \mathrm{~m}^{3}$ per year. This situation is worsening as the crisis continues with permanent negative impacts to the sector. Most timber industries or timber traders in the market face huge losses to their income and a huge decline in demand. Many others, mostly small firms with 10 to 15 workers on average are being forced to close.

b) Production, consumption and trade balance

At first sight, Figures 1, 2 and 3 suggest that Greece traditionally is facing a deficit in forest products. In all the cases, the consumption of the products seems to be higher in production and the trade balance is continuously, and in all the categories, negative in value, indicating that imports are overlapping the exports. According to Figure 1 it is obvious that after 1960 the sawnwood consumption is constantly larger than its production, increasing further after 2000 , but declining after 2008. Simultaneously the production seems to be slight, a fact that confirms the inability of the national forest sector to sufficiently supply the national need, which was expected. Those needs seem to have been met by the increased imports, which kept the trade balance having negative values during the examined period. After 2008 an offset of the balance is observed together with a decrease in consumption.

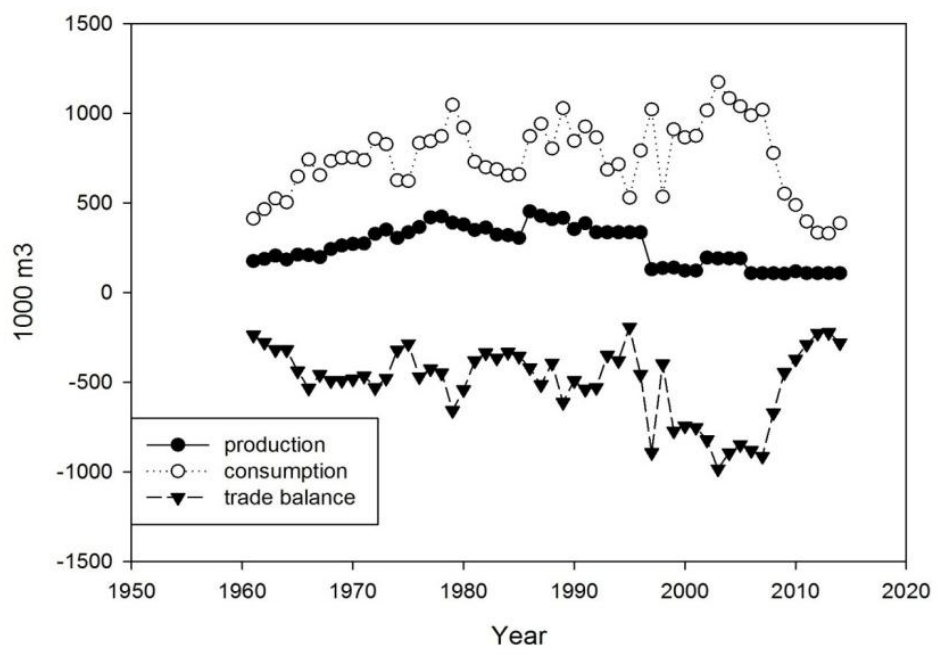

Figure 1. Greek sawnwood production, consumption and trade balance during the decades

\footnotetext{
${ }^{1}$ Based on 2011 data (ETTF, 2011). 100 members are listed on the Hellenic Timber Association website, representing the entire spread of the timber trade in Greece. In this list are included chipboard, MDF and some flooring producers, structural timber suppliers, timber agents, importers, and distributors around the country (Albanis Y, 2017).
} 


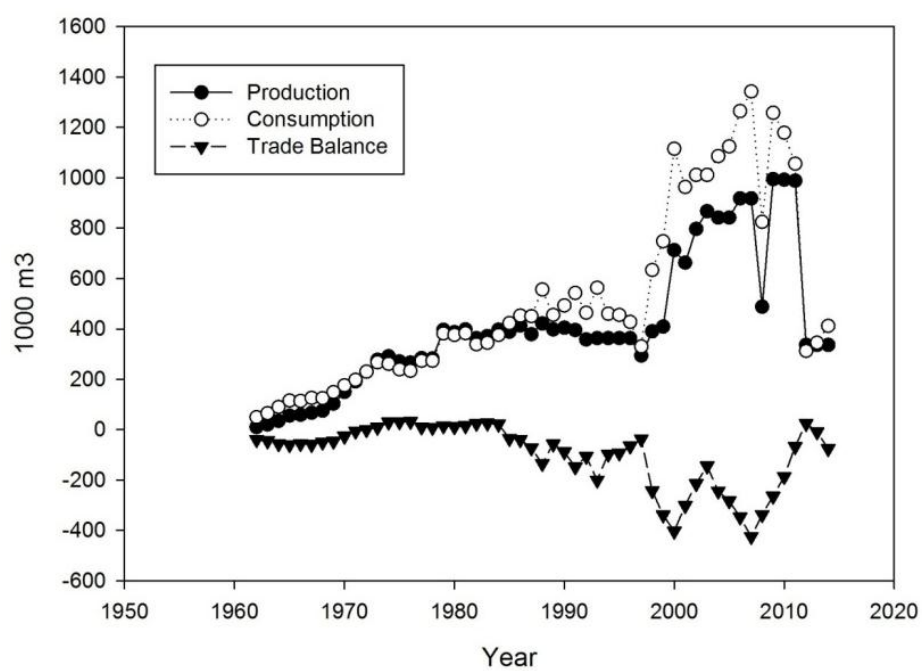

Figure 2. Greek wood based panels production, consumption and trade balance during the decades

Source: FAOSTAT

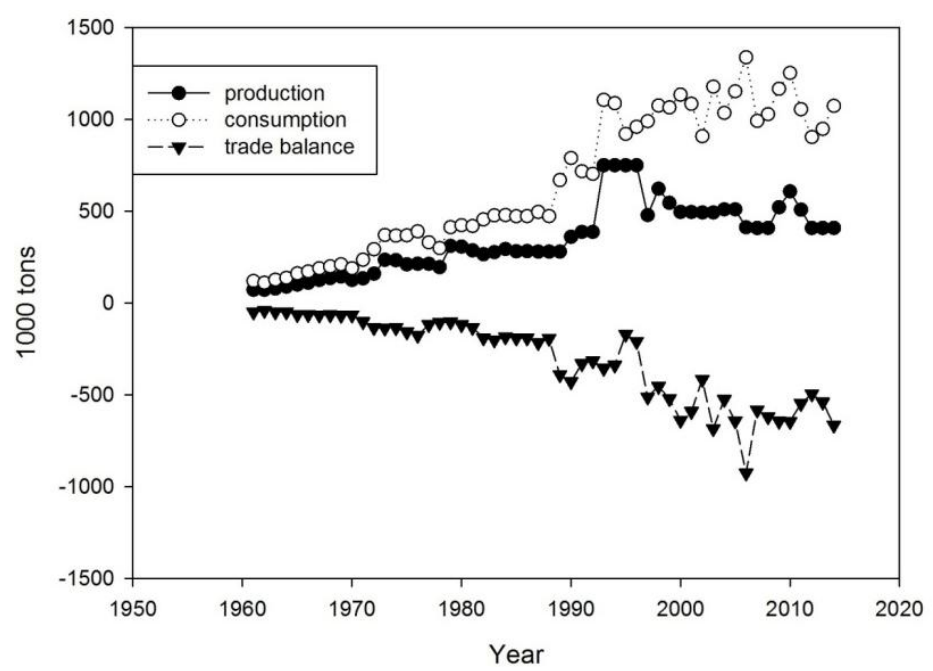

Figure 3. Greek paper and paperboard production, consumption and trade balance during the decades

\section{Source: FAOSTAT}

The main characteristic regarding wood-based panels trade (Figure 2) is the trade deficit. Nevertheless, the production seems to follow consumption for panels and the consumption is more connected with the domestic production following similar ups and downs. This observation obviously is related to the domestic industries and their production. Their productivity surely cannot satisfy domestic needs but it seems that a big part of the production is consumed at a national level. On the other hand, when the consumption falls for an external reason, production follows and vice versa. It is easy to confirm this interaction after the 2008 financial crisis. In parallel, during the last several years the trade deficit of 
wood panels tends to zero, possibly due to the increase of exports. The total exports in forest products, measured in $\mathrm{m}^{3}$, between 2008 and 2014 reached the levels of 194,046 $\mathrm{m}^{3}$ from $127.590 \mathrm{~m}^{3}$ (total increase 52\%) (Koulelis, 2016). More specifically, according to FAOSTAT, the exports of wood panels during the same period increased by $85.8 \%$. In addition, production and consumption have experienced a significant decrease that has reached approximately to the levels experienced before 2000. The trade deficit of paper and paperboard seems to be inflated during the decades (Figure 3). The difference between consumption and production has been increasingly getting bigger, especially since the mid-90's. Paper consumption has maintained steady growth for many decades, easily keeping up with the growth of GDP as was expected. It can be observed that production follows the increasing needs in general, but after the 90's the difference between them has increased. The trade balance is increasingly growing, showing the increasing levels of imports over the years. It is also reported that significant progress has been made in the area of packaging producing during the previous years. Greek legislation obliges all enterprises that produce or trade packaged goods for the domestic market to be responsible for the collection and recycling of the packaging they use. Paper-cardboard and liquid cartons are being produced in large quantities, mostly collected from packaging waste from all sources. Slight signs of a better performance in terms of national production are observed here.

c) Demand models, meaningfulness of variables

Table 1 presents the results of the multiple log-log regression analysis regarding the calculated projection functions of sawnwood, wood panels, paper/paperboard and wood fuel demand. The meaningfulness of variables with impact to demand was examined as well. The results based on data during the period 1970-2014.

According to the table 1 the independent variables income per capita and import prices were found to be significant considering the apparent consumption per capita of wood panels, paper and paperboard and wood fuel. On the contrary sawnwood consumption cannot be explained by the particular independent variables possibly due to bad quality of input data. The adjusted R-squared of the models were $0.380,0.558$ and 0.566 respectively with $p$ value under 0.05 in most of the cases. Looking at the Variance inflation factor it's easy to understand that multicollinearity among the variables is not a constraint because VIF in all the cases is under than 10 .

Regarding the panels consumption income and import prices were found to be statistically significant for the depended variable $\left(p_{b}=0.023\right.$ and $\left.p_{d}<0.001\right)$. The calculation of the standardized coefficients indicate import price the most meaningful variable (Std. Coeff.= 0.54) considering the absolute values. The results seem reasonable for a net importer country. However, changes in income are surly play important role to the panels demand because the biggest demand of panels rising up together with the income increase (positive relationship).

Considering the paper and paperboard consumption, both variables are significant and important for the model $\left(p_{b}=0.002\right.$ and $\left.p_{d}<0.001\right)$. At the same time, the import prices variable once again has the biggest standardized coefficient (0.50). Like panels import, prices seem to have the biggest impact on paper and board demand of Greece. 


\section{Macrothink}

The multiple double log-linear model regarding fuel wood consumption is also statistically acceptable with $R^{2} a d j$ equal to 0.566 . The significance for income is acceptable $\left(p_{b}=0.004\right)$ contrary to the import prices significance which is not $\left(p_{d}=0.151\right)$. Moreover, regarding the meaningfulness of the variables, we can only consider income, which is statistically important and has a standardized coefficient equal to 1.19 (considering the absolute values).

Table 1. Wood products demand as a function of multiple variables ${ }^{\mathrm{a}}$

\begin{tabular}{|c|c|c|c|c|c|c|c|}
\hline & $a(C S E)$ & $b(C S E)$ & $d(C S E)$ & $R^{2} a d j$ & $P(b)$ & Std. Coeff $(b)$. & $V I F(b)$ \\
\cline { 5 - 8 } & & & & & $P(d)$ & $S t d$. Coeff $(d)$. & $V I F(d)$ \\
\hline $\begin{array}{c}\text { Sawnwood + (total) } \\
\text { Consumption per capita }\end{array}$ & n.a.* & n.a. & n.a. & n.a. & n.a. & n.a. & n.a. \\
\cline { 5 - 8 } & & & & & n.a. & n.a. & n.a. \\
\hline $\begin{array}{c}\text { Wood Panels + (total) } \\
\text { Consumption per capita }\end{array}$ & $13.266(0.68)$ & $0.07(0.06)$ & $0.7(0.18)$ & 0.380 & 0.023 & 0.16 & 1.313 \\
\hline $\begin{array}{c}\text { Paper and board + (total) } \\
\text { Consumption per capita }\end{array}$ & $12.47(0.41)$ & $0.14(0.04)$ & $0.67(0.15)$ & 0.558 & 0.002 & 0.38 & 1.28 \\
\hline $\begin{array}{c}\text { Wood fuel +(total) } \\
\text { Consumption per capita }\end{array}$ & $22.29(2.57)$ & $-0.75(0.21)$ & $0.24(0.16)$ & 0.566 & 0.004 & -1.19 & 3.74 \\
\cline { 5 - 8 }
\end{tabular}

${ }^{a}$ Model form: $\ln \operatorname{Cons}_{\mathbf{t}}=\mathbf{a}+\mathbf{b} * \operatorname{lnGDP} / \mathbf{c a p}_{\mathbf{t}}+\mathbf{d} * \ln \mathbf{P}_{\mathbf{t}}$, a: Constant, b: Income per capita (US \$/cap) coefficient, d: import price coefficient, CSE: Coefficient Standard Error, $R_{\text {adj: }}^{2}$ Adjusted coefficient of determination, $p$ : significance, Std. Coeff: standardized coefficient, $V I F$ : Variance inflation factor.

*n.a.: Not applicable

One variable in every case that is included in the models is indicated as more meaningful. This doesn't mean that the other is not having an impact on the dependent variable. e.g. the impact of import prices is surely related to the demand of fuel wood, but in the particular model (Table 1), the above variable doesn't seem to be significantly important, at least when its impact on the other variables is collateral. In the analysis, the selection of the two variables together that have an impact on demand was preferred in order to understand how they are impact together over a long time period. This rationale had better success on panels and paper demand where both variables seem to be important when they affect together. Finally, all the above results are generally consistent with economic theory.

Thus, the results tend to imply a substitution between imports and domestic production in consumption. Moreover, when income declines, the demand for fuel wood increases instead of the other two categories, where the demand declines. The reverse fuel wood trend with income seems to be expected because the national production of fire wood (included in the fuel wood category) is very important for people who live around the forests in highland areas. The demand for fire wood in these cases is quite large. In addition, during the last decade the demand for firewood, even in big cities, has increased due to increases in oil price taxes and the economic crisis. Further analysis of factors that are affecting the wood fuel demand is proposed, especially in this case.

As was mentioned in the methodology section, the particular model we used allowed us to 
estimate simultaneously the income and import prices elasticities of the selected categories (equation 2). In most cases, the income elasticity was positive ( 0.07 for wood-based panels and 0.14 for paper and board consumption) apart from the wood fuels category which seems to be negative (-0.75). This could be explained easily by thinking that wood fuel, in particular fire wood, in Greece, is preferred by consumers when their income decreases and their usual preference of other heat alternatives like oil or electric power becomes almost impossible due to their high cost.

Furthermore, the import price elasticity of demand was calculated. For panels it was 0.67 , for paper and board it was 0.7 and for wood fuel, it was estimated at 0.24 . The results show that all the categories are import price elastic, which implies some kind of competition between domestic and foreign producers in the face of an adjustment in demand. For example, increasing imports prices generally tend to increase the demand for domestically produced goods, which then leads to reduced imports.

The above models could be useful for the wood industry or to the policy makers in terms of future planning. Imports or production through forest management could be planned. Moreover, the quantity and the quality of the wood that is produced inside the borders could be determined as much as possible. This kind of knowledge could indirectly be helpful to improve or to establish sustainable forest management in Greece that aims to increase production of certified products from certified forests or from new plantations. The analysis of the factors that influence the demand could be used as a tool in order to face up to future demand when this is necessary. A specific certification program could help on this occasion. In general, the forests in Greece are managed based on a sustainable way but without under a specific certification. Although, one of the main forest management approaches ${ }^{2}$ for Greece is wood production, even in a limited range. A new forest policy plan that includes the development of the current ecosystems and the creation of new ones based on reforestation or afforestation (with a smart choice of tree species) could possibly lead to an important increase in production. A possible participation of Greece in a forest certification organization and the development of a SFM certification system, which would cover all types of forests and forest matters, might increase the recognition of the contribution of forestry to the economic development of the country through the broad participation that certification brings (Georgiadis et al., 2007). According to Global Forest Resources Assessment (2015) in Greece the area of forest under an independently verified forest certification scheme between 2005 and 2009 was approximately around $35000 \mathrm{Ha}$. Before and after these years there are no certified forest areas. One particular plan for future consumption could be a guide for imports in the market and possibly could help to avoid uncontrolled imports that injure the trade balance. Sequentially, it might help to lead the consumers to substitutes that are produced at the national level.

\footnotetext{
${ }^{2}$ The others are a) Non-wood production: resin, honey, livestock, mushrooms, pharmaceutical wild-plants and b) Social uses: wildlife, recreation, hunting (Spanos et al., 2015) . In addition, new management strategies adapted to a changing climate should be quickly integrated into this sustainable forest management of forest ecosystems as FAO suggests (FAO, 2013).
} 


\section{Conclusions}

In all the cases that were presented, the consumption of wood and wood products seems to be higher than production and the trade balance has a negative value indicating that imports are exceeding the exports. The study also investigates the Greek demand of four wood products categories. The most meaningful variables with impact on the demand were underlined. Import prices were found to be statistically significant and meaningful for panels and paper demand, and income was found significant and meaningful for fuel wood demand. Furthermore, the demand for the above categories was found to be elastic to income and import price following all the cases. Only wood fuel demand was found to be inelastic to income. The results show the importance of income and import prices in demand after a simultaneous effect for a period of more than 50 years. Further research in this area is suggested for every special category and subcategory. More generally, it is easy to understand that there is clearly space for further theories on the factors affecting wood and wood products demand per capita in Greece. The study follows tested, worldwide used methodology. Although one advantage is that takes into account the economic crisis. The construction of the models is based on updated data which somehow include the implications of the crisis to GDP, import prices and demand.

Conclusively the model characteristics indicate some policy implications. The need for an increased qualitative production after a total revision of the national forest policy is underlined. Bigger productions could be achieved only with new plantations (exploiting the advantages of short rotations, (Populus spp. and Cupressus spp. have been proposed in the past for this reason) in parallel with the development of the current forest ecosystems. For the purpose of this development, future targeted research on the testing and use of valuable native trees and shrubs is proposed by many researchers. The experimental data are few, although Greece is a hot spot for biodiversity around the world with more than 6600 plant native species. In particular, the vascular flora of Greece consists of a total of 5.752 species and 1.893 subspecies (native and natural), representing 6.600 taxa (Dimopoulos et al., 2013).

It is known that Greek forest policy is currently giving more attention to the conservation and protection of the national forest ecosystems, although the need for wood products - not only technical wood - has increased over the past decades. Until now, whenever the demand was increased, which could be for many reasons, the only choice was to increase imports. Some other options, such as stopping the storage of forest natural capital and better utilization based on sustainable forest management are suggested. Until now there has not been the framework for the development of certification schemes and implementation of labeling systems related to sustainable management of forests and production of wood products; even forest management in Greece is based on sustainability rules. The above new options could be an opportunity for new investments on forest resources.

\section{References}

Albanis, Y. (2017). Hellenic Timber Association. Retrieved from http://www.ettf.info/hellenic-timber-association 
Arabatzis, G., \& Klonaris, S. (2009). An Analysis of Greek Wood and Wood Product Imports: Evidence from the Linear Quadratic Aids. Forest Policy and Economics, 11, 266-270. http://dx.doi.org/10.1016/j.forpol.2009.04.002

Baudin, A., \& Brooks, D. (1995). Projections of wood products demand, supply and trade in ETTS V. ECE/TIM/DP/6 UNECE, Geneva, Switzerland.

Baudin, A., \& Lundberg, L. (1987). A world model of the demand for paper and paperboard. Forest Science, 33(1), 185-196.

Buongiorno, J. (1977). Long-term forecasting of major wood products consumption in developed and developing economies. Forest Science, 23(1), 13-25.

Buongiorno, J. (1978). Income and Price Elasticities in the World Demand of Paper and Paperboard. Forest Science, 24(2), 231-244.

Buongiorno, J., Zhu, S., Zhang, D. [et al.] (2003). The Global Forest Products Model: structure, estimation, and applications. Academic Press/Elsevier. San Diego.p. 301.

Cohen, J., \& Cohen, P. (1983). Applied Multiple Regression/correlation. Analysis for the Behavioral Sciences. Second Edition. Lawrence Erlbaum Associates, Inc. NewJersey.

Dallal, G. E. (2001). The Little Handbook of Statistical Practice. Retrieved from http://www.jerrydallal.com/lhsp/LHSP.HTM

Dimopoulos, P., Raus, Th., Bergmeier, E., Constantinidis,Th., Iatrou, G., Kokkini, S., Strid, A., \& Tzanakoudakis, D. (2013). Vascular plants of Greece: An annotated checklist. (page 28). Berlin: Botanischer Garten und Botanisches Museum Berlin-Dahlem; Athens: Hellenic Botanical Society. [Englera 31]

Draper, N., \& Smith, H. (1981). Applied regression Analysis. John Wiley and Sons, Inc, New York.

European Timber Trade Federation ETTF. (2011). Statistics - Greece. Timber trade monitoring in support of effective, efficient and equitable operation of the EU Timber Regulation (EUTR). Rupert Oliver, Forest Industries Intelligence Limited, The Little House, 18 Church Street, Settle, North Yorkshire BD24 9JE, U.

FAO/FRA. (2015). Global Forest Resources Assessment, Country Report, Greece. Rome 2014.

FAO. (2010). Food and Agriculture Organization of the United Nations. Forest products definitions. Rome.

FAO. (2013). The State of Mediterranean Forests 2013 (SoMF 2013). Rome.

FAO. (2013a). State of Mediterranean forests 2013. FFEM, Silva Mediterranea, Plan Bleu, Food and Agriculture Organization of the United Nations. FAO, Rome.

Food and Agriculture Organization of the United Nations (FAO) FAOSTAT). 2016: Available in http://faostat.fao.org/site/626/default.aspx\#ancor [access on 2016]. 


\section{I Macrothink}

Environmental Management and Sustainable Development

ISSN 2164-7682

2017, Vol. 6, No. 2

Frost, J. (2016). How to Identify the Most Important Predictor Variables in Regression Models. Retrieved from

http://blog.minitab.com/blog/adventures-in-statistics-2/how-to-identify-the-most-important-pr edictor-variables-in-regression-models.

Georgiadis, N., \& Cooper, R. (2007). Development of a Forest Certification Standard Compatible with PEFC and FSC's Management Requirements. A Case Study from Greece. Forestry, 80, 113-135. http://dx.doi.org/10.1093/forestry/cpm004

Hurmekoski, E., Hetemäki, L., Linden, M. (2015). Factors affecting sawnwood consumption in Europe. Forest Policy and Economics, 50, 236-248.

https://doi.org/10.1016/j.forpol.2014.07.008

Jonsson, R. (2011). Trends and Possible Future Developments in Global Forest-Product Markets-Implications for the Swedish Forest Sector. Forests, 2, 147-167.

https://doi.org/10.3390/f2010147

Kangas, K., \& Baudin, A. (2003). Modelling and Projections of Forest Products Demand, Supply and Trade in Europe. A study prepared for the European Forest Sector Outlook Study (EFSOS) GENEVA TIMBER AND FOREST DISCUSSION PAPERS FAO.

Koulelis, P. (2009). Cluster Analysis in Primary Roundwood Production of 25 Countries of European Union. Annals of Forest Research, 52, 163-168.

Koulelis, P. (2011). Greek Timber Industries and Wood Product Markets over the Last Century: Development Constraints and Future Directions. Annals of Forest Research, 54, 229-240.

Koulelis, P. (2016). Forest Products Consumption and Trade Deficit in Greece during the Financial Crisis: A Quantitative Statistical Analysis. Open Journal of Business and Management, 4, 258-265. http://dx.doi.org/10.4236/ojbm.2016.42027

Matis, K. (2004). Introduction in the regression. Publications Pegasus 2000, Thessaloniki.

Palahi, M., Mavsar, R., Gracia, C., Birot, Y. (2008). Mediterranean forests under focus. International Forestry Review, 10(4), 676-688. https://doi.org/10.1505/ifor.10.4.676

Solberg, B. (1986). Forest sector simulation models as methodological tools in forest policy analysis. Silva Fennica, 20, 419-427. https://doi.org/10.14214/sf.a27757

Spanos, I., Meliadis, I., Platis, P., Mantzanas, K., Samara, T., \& Meliadis, M. (2015). Forest Land Ownership Change in Greece. COST Action FP1201 FACESMAP Country Report, European Forest Institute Central-East and South-East European Regional Office, Vienna. 31 pages. [Online publication]

UN. (2005). European Forest Sector Outlook Study: Main Report. United Nations. FAO/UNECE Agriculture and Timber Division, Timber Branch, Geneva, Switzerland.

UNECE/FAO. (2011). The European Forest Sector Outlook Study II 2010-2030. EFSOS II. United Nations publication. 
UNECE/FAO. (2012). The European Forest Sector Outlook Study II 2010-2030. EFSOS II. United Nations publication.

UNEP/MAP-Plan Bleu. (2009). State of the environment and development in the Mediterranean.UNEP/MAP/PlanBleu,Athens,Greece.http://planbleu.org/sites/default/files/pu blications/soed2009_en.pdf [access on 15 February 2016]

Zhu, S., Tomberlin, D., Buongiorno, J. (1998). Global forest products consumption, production, trade and prices: global forest products model projections to 2010 Global Forest Products Outlook Study Working Paper No: GFPOS/WP/01 Department of Forest Ecology and Management Forestry Policy and Planning Division, Food and Agriculture Organization, Rome.

\section{Copyright Disclaimer}

Copyright for this article is retained by the author(s), with first publication rights granted to the journal.

This is an open-access article distributed under the terms and conditions of the Creative Commons Attribution license (http://creativecommons.org/licenses/by/3.0/). 